\title{
Effect of Workforce Diversity on Job Performance of Hotels Working in Jordan
}

\author{
Ayat Mohammad "Esam Saed" Mohammad ${ }^{1}$ \\ 1 Assistant Prof of Strategic Management, Business Administration Department, Faculty of Money and \\ Management, The World Islamic Sciences and Education University, Amman, Jordan \\ E-mail: Ayat Mohammad "Esam Saed" Mohammad, Assistant Prof of Strategic Management, Business \\ Administration Department, Faculty of Money and Management, The World Islamic Sciences and Education \\ University, Amman, Jordan. E-mail: dr_ayatt@yahoo.com
}

Received: January 28, 2019

Accepted: February 15, 2019

Online Published: March 8, 2019

doi:10.5539/ijbm.v14n4p85

URL: https://doi.org/10.5539/ijbm.v14n4p85

\begin{abstract}
Implementing workplace diversity has become a major focus in many Human Resource departments. Diversity workforce can contribute to the organization's success by enabling access to a changing marketplace via the organization's multicultural employees. This study aimed to examine the impact of workforce diversity on the job performance in hotels operating in Jordan. Four dimensions of workplace diversity were included in the study: Gender, Age, Nationality, and Education background, on the other hand, job performance was measured by two dimensions: task performance and contextual performance. The study population consists of all managers working at different managerial levels in hotels in Jordan; samples of 389 managers were selected to represent the study population. Data were collected using a questionnaire developed on the strength of previous studies. Both IMB SPSS 19.0 and AMOS 23.0 were run to examine and test measures, data and hypotheses.

The results of the study supported the hypotheses that workforce diversity dimensions; Gender, age, nationality and educational background have a positive impact on job performance. Based on the study results the researchers recommend managers and decision makers of hotels in Jordan need to create better diversity management action plans in order to better accommodate the changing business environment.
\end{abstract}

Keywords: workforce diversity, job performance, hotels, Jordan

\section{Introduction}

God created everything in this universe in terms of color, shape, gender and many other aspects that made diversity a reality that people are aware of, and deal with daily in all aspects of their lives. This diversity also applies to organizations and their employees. Organizations are diverse in their forms, objectives, plans; it also obliged managers in the organizations to look for the best ways to manage this diversity in order to benefit from it in order to achieve organizational goals. Workforce diversity deals with different aspects of the labor force. Which are based on the individual view of their differentiation based on age, working conditions, gender, trends, race, social status, geographic region, work experience, income and nationality, which can contribute in supporting the basic organizational value (Kyalo, 2015).

Managers within organizations are responsible for the success of workforce diversity policies by creating an effective diversity policy that ensures recognition, and response to all differences in order to ensure the retention of talented employees, because when diversity is not properly managed, there will be organizational problems such as high turnover and communication difficulties, and conflicts among workforce, which negatively affects the productivity of the organization and achieve its goals. The workforce diversity indicates a homogenous mix of workforce which is diverse in terms of gender, age, nationality and educational background (Robbins \& Judge, 2009). The workforce diversity affects the management practices and policies of the organization as the characteristics of the workforce influence the way they think and interact with events and activities.

In a climate of tension and division of labor such as the hotel sector climate, job performance becomes one of the main challenges faced by managers, and the reason is that performance is closely related to efficiency, knowledge management and quality from one side, and management, finance and organizational development from the another side (Al-Hawary et al., 2013). Job performance is an important infrastructure in organizational 
practice and research, because of the key role it plays in most employee's decisions such as compensation based on merit, motivation, and retention (Al-Hawary, 2015; Al-Hawary \& Shdefat, 2016; Scullen, Mount \& Goff, 2000). Employees' performance is one of the most important reasons that achieve the objectives of the organization as most organizations need to focus on it.

Job performance is critical factor in determining the organizational performance (Al-Hawary \& Al-Kumait, 2017). Previous literature has shown that employees who are not properly matched to job characteristics have a low job performance (Hawary \& Alajmi, 2017). Matching the person with the job in the organization can be a real indicator of job performance, because it has been shown that individuals who match the job more have higher functional outcomes (Al-Hawary \& Al-Namlan, 2018; Al-Hawary \& Nusair, 2017; Edwards, 1991).

Researchers have addressed job performance in many studies, which hypothesized several studies that have a positive effect on job performance. Bass et al. (2003) assert that transformational leadership positively correlates to managerial performance. Job performance affects the procedure of rational decision making (Mohammed et al., 2013). Singh (2016) examines the influence of internal service quality (ISQ) on job performance in the public sector results indicate that internal service quality is positively correlated with job performance. Platisa et al. (2015) noted that job satisfaction is an indicator of job performance. Job performance is directly and strongly related to stress and burnout. Mihalcea (2013) and Salanova et al. (2011) identifying the Correlating of the leadership styles with the degree of professional job performance. Emotional intelligence is one of the most important factors which would result to a higher level of job performance (Watkin, 2000; Mafuzah \& Juraifa, 2016; Nooraei \& Arasi, 2011). Salgado (2017) predicting job performance by testing the moderator effect of job complexity on the validity of forced-choice personality inventories. Nadiah et al. (2016) assumed that there was a relationship between the personality traits of the leader and job performance.

There have been numerous studies dealing with workforce diversity which have been operating in the Arab environment, but it has not been the luckiest of research studies on the feasibility of enhancing the job performance of employees. The researcher touched upon the scarcity of studies that dealt with the workforce diversity in the Arab environment, especially in the hotel sector, where there was a lack of studies that tested the subject comprehensively, and the results of this study may be very important to provide a guide to help identify the current challenges Which face the management of diversity, and thus improve the performance of organizations. The results of the study may also help to enrich the theoretical literature on the subject of workforce diversity and job performance. This study analyzes job performance at two levels; task performance and contextual performance.

This study is important because of the important role played by the workforce diversity in the success and continuity of organizations, and the importance of managing the workforce diversity in the job performance. The workforce diversity enhances the ability of the employees to perform their work effectively, and contributes to enhancing the creativity of the organizations through interaction and the exchange of experiences, cultures and backward knowledge among workers, that may put the organization on track (Mercy, 2012), this study provides a scientific explanation of the impact of the workforce diversity on the job performance, to be a study that helps decision makers in the field of manpower in organizations in general to take the decisions related to the workforce diversity.

This study enhances our concepts of workforce diversity, and how to raise the sense of belonging and efficiency in the work of employees, and thus improve their performance. This study deals with an important sector (the hotel sector) that affects the lives of people and contributes to various socio-economic indicators such as job creation and helping people improve their standard of living. The growth of the hotel sector and its contribution to the national product makes it an important area of study, especially when the matter dealing with enhancing employees performance, and identification of suitable candidates for important and diverse posts.

\section{Conceptual Framework and Hypotheses Development}

\subsection{Job Performance}

In a dynamic environment of much transformation and change, competitive organizations try to provide high service quality to their customers or stakeholders (Al-Hawary \& AL-Hamwan, 2017). Organizations operating in volatile environments also recognize that they must provide services in line with the needs and expectations of stakeholders. Successful organizations need to emphasize the quality of services provided to both internal and external customers (Metabis \& Al-Hawary, 2013; Al-Hawary \& Metabis,2012; Al-Hawary, 2013; Al-Hawary \& Abu-Laimon, 2013 ). These organizations are conscious enough to anticipate the changing needs of their customers, to focus on their organizational capabilities and provide high-quality services, and to take care of the quality of internal service as a tool for competitive advantage. Therefore, the work performance of the employee 
is crucial for service organizations and the high performance among employees is a major challenge to manage the provision of excellent services to customers at all levels. Job performance means the effectiveness of employees activities that make a payment to organizational goals (McCloy, Campbell, \& Cudeck, 1994; Motowidlo, 2003).

Performance is one of the concepts that have received considerable attention and research in management studies in general, and human resources studies in particular, because of the importance of this concept at the individual and the organization, and the interaction between the influences that affect performance and it is diversity. The term "performance" or performance of the task is the implementation of the functional burdens of responsibilities and duties by the employee (Uchhal \& Solkhe, 2017).

Farooqui and Nagendra (2014) believe that job performance plays a critical role in the organization's performance. Lu et al. (2015) refers to the performance term, that behavior, achievement and performance should not be confused. Behavior is the work of individuals in their organization. Achievement is the effect or outcome that individuals make on work. Performance is the interaction between behavior and achievement, that is, the sum of behavior and results achieved together. Job performance reflects the financial and non-financial outputs of employees directly related to the organizational performance (Anitha, 2014).

Managerial Literature is full of definitions, models and methods to assess and understand the job performance, theories and practices were developed to enable professionals in human resources to enhance job performance directly (Holton \& Yamkovenko, 2008). In general, job performance is defined as actions or behaviors relevant to goals of the organization (Campbell, 1990), which includes employee behaviors that are positive or counterproductive to contribute to the achievement of organizational objectives or failure to achieve them (Hunt, 1996). Viswesvaren and Ones (2000) presented a more recent definition of job performance as behavior and outcomes that employees undertake which contribute to organizational goals. Job performance refers to the effectiveness of individual behaviors that contribute to organizational goals, which should consist of task performance and contextual performance (Motowidlo, 2003). Awadh and Wan (2012) defined job performance as employee participation to achieve organizational goals. Job performance is one of the important independent variables that have been studied for a long decade. Job performance also means the effectiveness of employees' activities by enhancing organizational goals (McCloy, Campbell \& Cudeck, 1994). Vithanage \& Arachchige (2017) defined job performance as: objective functional behavior not only as a result of forces or pressures resulting from the individual, but as a result of the interaction and harmony between the inner powers of the individual and the external forces surrounding him.

Many researchers agree that job performance is a multidimensional variable. In general, job performance consists of two dimensions: task performance and contextual performance (Borman \& Motowidlo, 1993; Borman and Motowidlo, 1997; Motowidlo \& Schmit, 1999). Reilly and Aronson (2012) consider that task performance behaviors directly or indirectly affect the substance of an organization's work (methods used by the organization to produce goods and services). Task performance behaviors are predetermined within the job description, and has relationship to the knowledge, experience, skills and abilities possessed by the employee, which vary depending on the job itself. Contextual performance behaviors influence the prevailing social and psychological environment of the organization, which means the environment in which goods and services are produced, in addition contextual performance behavior is not defined in the job description, but rather belongs to the employee himself, and is associated with other characteristics such as the personality and motivation of the employee (Reilly and Aronson, 2012).

\subsection{Concept of Work Force Diversity}

As a result of globalization, workforce diversity of the organizations has increased. It has become clear through researches that diversity has an impact on the achievement of various organizational tasks and roles, thus providing excellent services to customers, and maintaining a sustainable competitive advantage. Workforce diversity reinforced the vision of managers towards a clear and understandable adoption of the workforce diversity at the various locations of the Organization in order to obtain its advantages (Chew et al., 2011). Organization uses workforce diversity to improve its productivity and employees' income. Therefore, some important factors and characteristics must be taken into account. Dike (2013) refers to a number of factors such as the type of organization, where organizations vary in size and activities tend to employ more manpower because of their size compared with other organizations, managerial culture, each organizational culture is unique and different from any other organization, any organization's decision on diversity in the workplace is based on the organization's beliefs and rules, the organization's location where the organization's position contributes to the decisions of employing a diverse workforce. Organizations with international branches have 
greater options for employing human resources from diverse cultures.

Wentling and Palma-Rivas (1998) referred to some definitions of the workforce diversity, indicating that the diversity of the workforce is related to gender, age, nationality, scientific qualification, religious ideology, and physical or intellectual disability. While noting that the diversity of the workforce could extend to personal values, characteristics, education, language, physical dimension, social status, lifestyle, beliefs and background characteristics of geographical origin, location or status within the organization and the economic situation. Workforce diversity mentions the employee's specific similarities and differences. It views for individualism that comprises age, working environment, gender, perceptions, ethnicity, marital status, region, work experience, sexual alignment, income, nationality with each other, which support organizational essential values (Kyalo, 2015). Dessler (2011) defined workforce diversity as the multiple demographic characteristics that characterize workforce in the organization, particularly in terms of gender, culture, national origin, age, religion, etc. Carrell (2006) defines workforce diversity as the ways that people differ which can affect a task or relationship within an organization such as age, gender, race, education, religion, and culture. While Wambui et al. (2013) defined workforce diversity as demographic, physical, biological, social and psychological differences that make a difference between people. Mor Barak (2011) defines workforce diversity as the division of workforce into different categories such as - ethnicity, gender, race, age, disability - that a) have a perceived commonality within a national and cultural context and that $b$ ) influence possibly either detrimental or advantageous the employment outcomes such as job opportunities, treatment in the workplace and promotion prospects regardless of job-related skills. Phillips \& O'Reilly (1998) has referred to the workforce diversity as labor-force variances around any feature that may lead to self-awareness, with reference to the different social and cultural identity of people who are together in a specific work environment or market. Mercy (2012) finds that workforce diversity affect employee performance at varying degrees considering both managers and no-managerial employees of the Bank.

\subsubsection{Workforce Diversity Measurements}

Researchers tackled the concept of workforce diversity from multiple dimensions, such as sex, age, nationality, scientific qualification and others. Table 1 shows the measurements of workforce as adopted by researchers.

Table 1. Measurements of workforce diversity by authors

\begin{tabular}{|c|c|}
\hline Author & Dimensions \\
\hline Hafiza \& Faiza ( 2015) & culture, working environment, language, education and experience \\
\hline Al-Ahmad \& Al-khawlani (2017) & gender, ethnicity, education \\
\hline Omankhanlen \& Ogaga-Oghene (2011) & ethnicity, gender, and function \\
\hline Darwin \& Palanisamy ( 2015) & age, gender, ethnic diversity \\
\hline Muhammad Rizwan et.al,( 2016) & gender, age, ethnicity, education \\
\hline Ehimare \& Ogaga-Oghene ( 2011) & gender, tenure, age, and ethnicity \\
\hline Rijamampianina \& Carmichael (2005) & 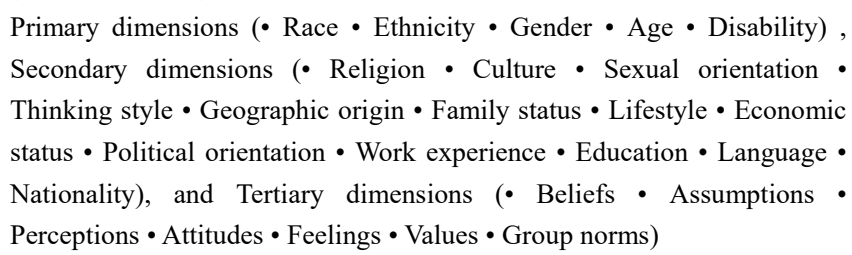 \\
\hline Gacheri(2012) & Age, sex, education \\
\hline Ankita (2014) & $\begin{array}{l}\text { Age, Gender, Professional qualification, Geographical regions, Language, } \\
\text { Caste and Religion, Different perception and attitude }\end{array}$ \\
\hline Kreitz (2008) & gender, age, ethnicity, nationality, education, or work status \\
\hline Carrel (2006) & age, gender, race, education, religion, and Culture \\
\hline Greenberg (2012) & $\begin{array}{l}\text { race, gender, ethnic group, age, personality, cognitive style, tenure, } \\
\text { organizational function, education, background }\end{array}$ \\
\hline Mor Barak (2011) & ethnicity, gender, race, age, disability \\
\hline
\end{tabular}

\subsection{Workforce Diversity and Job Performance}

Though it is usually known that here is limited research work on exactly how workforce diversity impacts job performance, but there is strong proof that workforce diversity has emotional impact on the working of 
organizations in terms of performance, negatively or positively (Ogbo et al., 2014).

Researchers dealt with the workforce diversity in research and analysis by studying its relationship with various managerial concepts. Akinnusi et al. (2017) emphasized the concept and importance of workforce diversity, especially the workforce diversity in the workplace in Nigeria. He pointed out that the practice of managing workforce cannot be separated from the social, cultural, economic, political and legal environments of the society. Al-Ahmad and Al-Khawlani (2017) referred that workforce diversity in the workplace may lead to a lack of communication and conflict if employers fail to manage it, and thus to the performance of employees. Mercy (2012) investigates the effects of workforce diversity management on employee performance in the Banking industry in Kenya. Hafizah \& Faiza (2015) found that languages and tribe, cultures and values impact on performance of the organization and Education diversity has positive relation with efficiency and effectiveness. Stazyk, Davis \& Jiaqi (2012) also suggests that diversity can benefit agencies by increasing individual and organizational performance. Bedi et al. (2014) addresses some of the challenges facing workforce diversity such as ethnicity, stereotypes and discrimination. Negative attitudes and behaviors can be barriers to managerial diversity, because they may harm labor relations, morale, and labor productivity (Esty et al., 2015). While Darwin \& Palanisamy (2015) concluded that the diversity of age, gender and ethnicity do not impact employees' performance. Thus is because the employees in Singapore neither admire the workforce diversity as a boon to them nor do they criticize it as a white elephant and they have shown a neutral perception about workforce diversity.

Gehrels and Suleri (2016) support that a diverse workforce is a crucial factor for the success of "authentic hospitality" The integration of employees with different background can bring within international hospitality industry: creativity, innovation, different abilities and multiple perspectives of solving problems - all of them can contribute to the hotel competitive advantage. Esty et al. (2015) indicates that workforce diversity is of great importance in that it achieves a high level of productivity, the exchange of creative ideas, and the promotion of teamwork. It creates an opportunity for the professional growth of employees based on learning processes, and enhances the relationship of the organization with different market sectors, finally, has a significant advantage for organization by enhancing the response and productivity of the team to adapt with changing environmental conditions. Cadrain (2008) supports that encouraging diversity is a powerful tool in Order to attract and retain the best employees and at the same time increasing the level of Organizational competitiveness. Workforce diversity increases creativity and Innovation, and simultaneously has a positive influence on organization's performance (Armstrong et al., 2010; Evans, 2014).

Ehimare and Ogaga-Oghene (2011) found significant correlation between some of the diversity variables as well as individual diversity variables with the measures of organizational effectiveness. Durga (2017) found significant correlations between some of the diversity variables, as well as individual diversity variables and organizational effectiveness. Rizwan et al. (2016) noted that there are many factors that can affect employees' performance such as gender, age, race and educational background of employees as expected variables for employee performance in the banking sector. Saltson and Özgür (2015) noted that workforce diversification has an impact on non-financial performance, and some demographic elements, such as gender, total tenure, and the labor sector, have the ability to influence performance. Hafizah \& Faiza (2015) also found that languages and tribe, cultures and values impact on performance of the organization.

\subsection{Gender and Job Performance}

The gender factor has attracted the attention of both researchers and practitioners, which has raised the question of whether gender differences in the workforce of organizations have an impact on individual or collective performance. It has been shown that gender diversity may create a difference in cognitive and skillful abilities such as male competence in accounting and women's ability to use verbal and personal skills. The combination of these abilities and competencies in a diverse team of both genders can promote creativity, and high quality decisions (Rogelberg \& Rumery, 1996). Priyam Dhani et al. (2017) examine the Gender Differences in Emotional Intelligence and that to find whether there is a significant difference between the EI scores of male and female respondents it was found that for female respondents EI is positively correlated with job performance, It was found that for male respondents EI is positively correlated with job performance. While many studies have confirmed some negative effect of gender diversity. Kravitz (2003) noted problems of gender communication, while Chatman \& Flynn (2001) noted problems of lack of cooperation and increased conflict between forces of both gender. Based on the review of the literature, a hypothesis was formulated as follows:

Gender diversity has a significantly positive effect on job performance. 


\subsection{Age and Job Performance}

Several studies have confirmed positive and negative effects of age difference. Backes-Gellner \& Veen (2009) noted that age diversity helps to affect a complementary collaborative effect among teams and working groups to enhance their productivity in achieving work, as well as positive effects of difference Ages are represented by the participation of staff in transferring knowledge and experience. The negative effects indicated by some researchers were the problems of interaction and the consolidation of social relations, in addition to the costs of communication compared to age groups. In addition, the difference in age can have other indirect negative effects on the level of productivity through increased turnover rates as well as the implications for social integration and conflict at work (Jackson \& Joshi, 2004). Based on the review of the literature, a hypothesis was formulated as follows:

Age diversity has a significantly positive effect on job performance.

\subsection{Education Background and Job Performance}

Hickman (2009) indicates that the individual is more productive depending on the level of education achievement and the greater the level of employee education, the greater the productivity of the labor force. Moretti (2004) shows that cities which have a higher proportion of the workforce with higher education are able to earn higher wages. Mamman (1996) points out that the highly educated workforce has positive attitudes towards new processes and environmental variables compared to the less educated workforce. Based on the review of the literature, a hypothesis was formulated as follows:

\section{Education background diversity has a significantly positive effect on job performance.}

\subsection{Nationality and Job Performance}

With regard to the extent to which differences in nationality affect the level of communication. Feely \& Harzing (2003) noted that differences in nationalities and multilingualism are a cause of ineffective communication, a cause of conflict, and a risk of decision-making. Thomas \& Eden (2004) noted that organizations which are diverse in their workforce in terms of nationality have a high impact on performance, but in the long run they may achieve a sustainable competitive advantage compared to other organizations. Based on the review of the literature, a hypothesis was formulated as follows:

Nationality diversity has a significantly positive effect on job performance.

\section{Research Hypothesized Model}

Figure 1 portrays the hypothesized model of the current research. The figure illustrates one main hypothesis postulated a non-significant impact of workforce diversity. Four sub-hypotheses were emerged from the main hypothesis. It was hypothesized that sex, age, nationality and educational level have non-significant impacts on job performance. The figure shows that the independent variable, i.e., workforce diversity was regarded as a multidimensional construct comprised Gender, age, nationality as well as educational level, while, on the other hand, the dependent variable, i.e., job performance was considered as an uni-dimensional construct. Hence, the impact of the workforce diversity and its related dimensions was examined on the job performance as a whole variable.

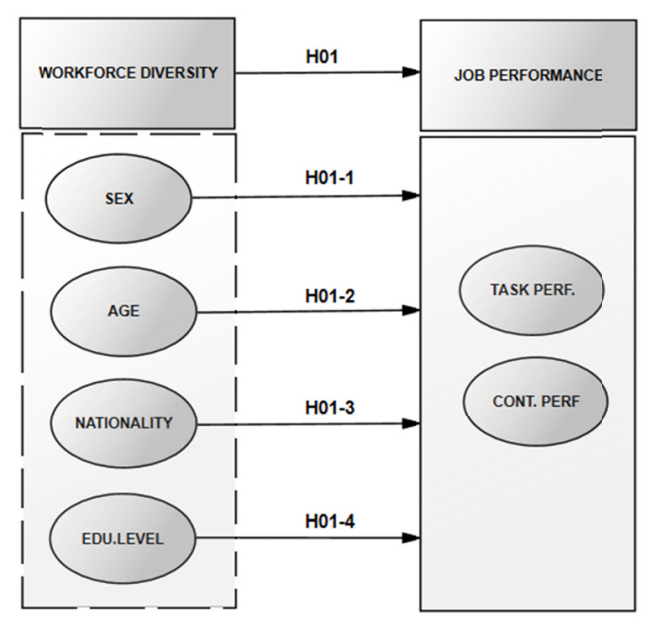

Figure 1. Research hypothesized model 


\section{Research Methodology}

\subsection{Research Sample Profile}

The sample of the current research comprised 400 participants selected from managers working at different managerial levels in hotels in Jordan. The results indicated that $73.8 \%(\mathrm{n}=287)$ of the sample was male and $26.2 \%(n=102)$ was female. Out of the participants, $45.2 \%(n=176)$ were in the age category 30 to less than 40 years, followed by $31.1 \%(\mathrm{n}=121)$ whose ages in the range of 40 to less than 50 years. The percent of those whose ages equal or higher than 50 years was $16.2 \%(n=63)$. In terms of participants' educational levels, the findings showed that the majority of them, i.e., $60.2 \%(n=234)$ had a bachelor degree, $31.4 \%(n=122)$ hold a master's degree and $8.4 \%(\mathrm{n}=33)$ had diploma degrees or less.

\subsection{Data Measurement and Collection}

A questionnaire was developed on the basis of Likert five-point scale, i.e., from $1=$ strongly disagree to $5=$ strongly agree. Dimensions of the independent variable were measured using 27 items (items 1-9 for sex, items 10-14 for age, items 15-20 for nationality, and items 20-27 for the educational level). Job performance was measured using 23 items (items 28-50). A total of 400 questionnaires were distributed to managers from different managerial levels. Out of those questionnaires, 389 questionnaires were completed and used in the current study.

\subsection{Reliability and Validity}

Reliability of the questionnaire used for the purpose of this study was assessed by composite reliability and Cronbach's alpha. Both these two measures should exceed 0.70 . Validity was measured by convergent validity, which can be evaluated by the average variance extracted (AVE) while the second one was analyzed with the help of the comparison held between the square root of AVE (AVE Sqrt.) and the squared correlations among latent variables. The value of each variable should be higher than the squared correlations between latent variables. The results of reliability and validity displayed in Table 2 showed an acceptable values of AVE, composite reliability and Cronbach's alpha. On the other hand, the results established an evidence in relation to values of AVE Sqrt. andthe squared correlations among variables. The correlation matrix demonstrated in Table 2 asserted that all values of AVE Sqrt. $(0.84-0.88)$ were higher that the squared correlations among variables $(0.01-0.22)$. Based on these results, reliability and validity of the instrument were confirmed.

Table 2. Results of reliability and validity

\begin{tabular}{lllllcr}
\hline Latent Variables & Items & AVE & AVE Sqrt. & $\begin{array}{l}\text { Construct } \\
\text { loading }\end{array}$ & $\begin{array}{c}\text { factor } \\
\text { Composite } \\
\text { reliability }\end{array}$ & $\begin{array}{c}\text { Cronbach's } \\
\text { alpha }\end{array}$ \\
\hline Gender & $1-9$ & 0.721 & 0.85 & 0.88 & 0.841 & 0.801 \\
Age & $10-14$ & 0.648 & 0.80 & 0.79 & 0.799 & 0.788 \\
Nationality & $15-20$ & 0.771 & 0.88 & 0.90 & 0.822 & 0.890 \\
Edu. level & $21-27$ & 0.698 & 0.84 & 0.78 & 0.884 & 0.841 \\
Job performance & $28-50$ & 0.759 & 0.87 & 0.87 & 0.805 & 0.794 \\
\hline
\end{tabular}

Table 3. The squared correlations

\begin{tabular}{|c|c|c|c|c|c|c|c|c|c|c|c|}
\hline \multirow{2}{*}{\multicolumn{2}{|c|}{ Variables }} & \multicolumn{2}{|l|}{1} & \multicolumn{2}{|l|}{2} & \multicolumn{2}{|l|}{3} & \multicolumn{2}{|l|}{4} & \multicolumn{2}{|l|}{5} \\
\hline & & $\mathrm{R}$ & $\mathrm{R}^{2}$ & $\mathrm{R}$ & $\mathrm{R}^{2}$ & $\mathrm{R}$ & $\mathrm{R}^{2}$ & $\mathrm{R}$ & $\mathrm{R}^{2}$ & $\mathrm{R}$ & $\mathrm{R}^{2}$ \\
\hline 1. & Gender & - & - & & & & & & & & \\
\hline 2. & Age & 0.11 & 0.01 & - & - & & & & & & \\
\hline 3. & Nationality & 0.14 & 0.02 & 0.19 & 0.04 & - & - & & & & \\
\hline 4. & Edu. level & 0.23 & 0.06 & 0.21 & 0.04 & 0.30 & 0.09 & - & - & & \\
\hline 5. & Job performance & 0.43 & 0.19 & 0.34 & 0.12 & 0.39 & 0.15 & 0.47 & 0.22 & - & - \\
\hline
\end{tabular}

* All correlations were significant at the 0.05 level.

\subsection{Research Structural Model}

Fitness of the structural model was assessed using five indices as shown in Table 4, which were Chi-square ratio to degrees of freedom $\left(\chi^{2} / \mathrm{df}\right)$, Goodness of fit index(GFI), Adjusted Goodness of Fit Index (AGFI), Comparative Fit Index (CFI) and Root mean Square Error of Approximation (RMSEA). The Structural Equation Modelling (SEM) was used to test the hypotheses of this study. The results of SEM revealed a significant positive impact of 
workforce diversity on job performance $(\beta=0.39, \mathrm{P}<0.05)$. Therefore, the main hypothesis $(\mathrm{H} 1)$ was supported. In relation to hypotheses H1-1, H1-2, H1-3 and H1-4, the results make known that Gender $(\beta=0.34, \mathrm{P}<0.05)$, age $(\beta=0.31, \mathrm{P}<0.05)$, nationality $(\beta=0.47, \mathrm{P}<0.05)$ and educational level $(\beta=0.27, \mathrm{P}<0.05)$ were significantly and positively affected job performance. Consequently, hypotheses H1-1, H1-2, H1-3 and H1-4 were accepted. Supporting these hypotheses designated that workforce diversity dimensions; Gender, age, nationality and educational level instigated job performance. The impact of nationality on job performance was higher that the impact of other dimensions.

Table 4. Structural model fit indices

\begin{tabular}{cccc}
\hline Index & Cut-off & Value \\
\hline$\chi^{2} / \mathrm{df}$ & $<3.00$ & 1.73 \\
GFI & $>0.90$ & 0.911 \\
AGFI & $>0.90$ & 0.920 \\
CFI & $>0.90$ & 0.900 \\
RMSEA & $<0.08$ & 0.03 \\
\hline
\end{tabular}

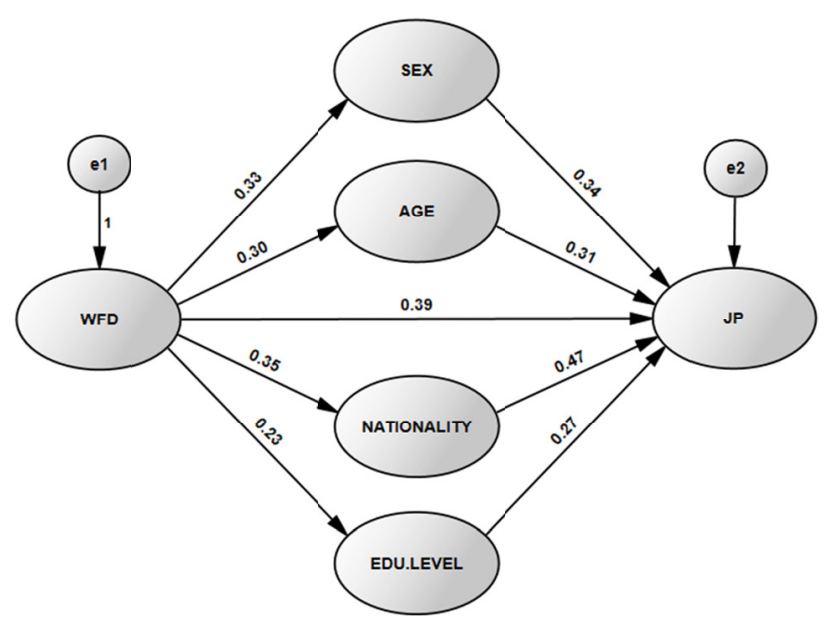

Figure 2. Research structural model

\section{Discussions}

Implementing workplace diversity has become a major focus in many Human Resource departments. In order to meet the demands of modern technologically advanced society, corporations must rethink what diversity means and how the concepts of developing, valuing, and managing a truly diverse corporation must go beyond traditional strategies (Easley, 2001: 38). Diversity management includes acceptance and respect, acknowledging that individuals are unique and different from each other (Lumadi, 2008), diversity employees can contribute an innovative approach towards organization which in turn can be a sustainable competitive advantage for the organization.

Almost everyone is now able to communicate and work with other people from different parts of the world due to the advancements in technology. One great proof of the technology advancement is the outsourcing of many administrative jobs. One of the tasks of managing workplace diversity is to recognize the differences among individuals and provide opportunities and means for individuals to contribute their talents to the organization. As previously stated, if a company recognizes the differences among its diverse employees, it will be able to create a work plan that optimizes productivity. The increase in productivity allows employees and managers to reach their goals within the organization.

This study aimed to examine the impact of workforce diversity on the job performance in hotels operating in Jordan. The business in hotels varies in terms of the content and duties required to perform them, including the variety of customers and other external entities that the sector deals with at the national and international levels, in order to adapt to the societies pressures, and the advanced technological economies, which justify the need to pay attention to workforce diversity in terms of gender, age, education, and others of differences to meet the 
different needs, and thus improve overall performance which is the result of improving job performance.

Researchers observed there is an influence of age diversity on the employee job performance which agrees with the findings discussed in Uschi and Stephan (2013) show that some firms are utilizing older employees for their knowledge and experience, as mentors for the younger team members. It has been observed seen from numerous studies that more old employee are as productive, profitable and skilful as young ones. Therefore, a heterogeneous age group of employees would be more creative, dynamic and gainful than a homogeneous age group (Williams and O’Reilly, 1998).

The hypothesis is accepted that there is significant impact of gender diversity on job performance. Hotels sector management have an preference to contract male workforce compared to female since they should have better performance and abilities to manage their jobs. While they are giving females a chance for work and improve their abilities and skills and join the decision making role in hotels. Gender diverse teams showed better problem solving and decision making skills than gender homogeneous teams. Gender diversity demonstrated a positive effect in the services industry and a negative impact on the assembling and manufacturing businesses. Consequently, service industry may advantage more from gender diversity than practices in the assembling and manufacturing commercial ventures. In this way, high gender diversity will have a more constructive outcome on employee and firm performance in the service industry than in the manufacturing industry. Similar to our observation, there are many researches which observed a significant impact of gender diversity, Gupta (2013) observed that moderate level of gender diversity increases competitive advantage while a higher level of gender diversity decreases organizational performance. In their opinion that gender diversity established significantly positive relationship with job performance which in turn result to positive firm performance.

The study showed a significant effect of nationality diversity on job performance of the employees in hotel sector in Jordan. The existence of different nationalities in the hotels' working environment creates a high diversity that may support the creative environment. On the other hand, it may create difficulties in understanding and communication, which may hinder the decision-making process and the performance of business in general. This may create a kind of personal conflict and weakness in cohesion, harmony between the employees, and this is consistent with the study of Ehimare and Ogaga-Oghene (2011), which found a statistically significant relationship to the culture diversity of workers on productivity. It further says that there is no any relationship between culture diversity and experience of employee on efficiency and effectiveness of employees (Hafizah and Faiza, 2015).

The study showed a significant effect of educational levels diversity on job performance of the employees in hotel sector in Jordan. Employees cannot find a well matched job and perform well without a sufficient education background. Teams that have divers education tend to have many internal issues dealing with pride and competitiveness amongst one another that may reduce productivity process due to unmade decisions by the group, These diversity teams also seem to have a higher rate of productivity simply because each brings a set of different tools to the table, from different kinds of experiences and trainings (Le, 2008). Hiring diversified workforce will definitely leads to improved productivity, but may prove to disaster if not managed properly because not only the management but employees are also feeling some problems like language problem (which is acceptable and is not due to thoughts of the employees), attitude clashes, and difference in perceptions, which is directly related to human behavior which ultimately affects the productivity of any organization Ankita and Saxena (2014). The result of the study is consistent with Hafizah and Faiza (2015) found a positive relationship between education diversity and efficiency, with also effectiveness. And consistent also with Choi and Rainey (2010) also found that a more prominent portion of educated workforces in a city mean higher financial development in that region. And inconsistent with the study of Durga (2015) which showed no casual relationship between education diversity and organizational effectiveness.

\section{Managerial Implications and Direction for Future Research}

Diversity workforce can contribute to the organization's success by enabling access to a changing marketplace via the organization's multicultural employees. A variety of workforce groups can explode creative ideas and offer solutions to the organization's problems, increasing organizational efficiency, effectiveness and profitability. Increase in the pool of qualified personnel from different backgrounds, and it widens the scope of eligible candidates for hire. Another benefit of a diverse workplace is it improves communication with an organization's clients. Managers should take it into consideration and they ought to deal effectively with challenges in order to retain the balance among people with diverse backgrounds within working environment.

Managers and supervisors deal with the challenge of motivating and keeping balance among their workers However, in order for an organization to utilize the workforce diversity properly, the implementation of diversity 
management practices seems the most sustainable solution.

The main goal of workplace diversity management is the prohibition of discrimination against individuals, which would cause them to be unfairly differentiated from coworkers. In addition to globalization, diversity has also increased as a result of an increase in women and people with disabilities entering the work force. Businesses should prioritize hiring diverse employees because of the many great things associated with it.

People have their own ways of learning, thinking, and dealing with things. It is more likely to be that a group composed of different minds; Facilitates learning processes, sharing knowledge and seeing problems from different perspectives, leading to creative solutions, and may be better able to detect and correct errors and problems before they occur. If the organization is able to understand the differences and diversity among its employees, it will be able to find a plan of action that increases the productivity of the employees. The increase in productivity enables the managers and employees of the organization to achieve their goals and thus the higher levels of organizational performance. Creating a strong diversity plan should be the first thing any business should do prior to embarking on anything related with a diverse workforce and workplace. Managers and decision makers of hotels need to create better diversity management action plans in order to better accommodate the changing business environment. Companies will need to create and or learn how to create a diverse workplace. "A strategy must be created and implemented to create a culture of diversity that permeates every department and function of the organization.

Harmonized teams of different nationalities will have a greater ability to find innovative solutions and create higher levels of understanding with the external environment, and customers from different cultures and nationalities, thus increasing the efficiency of employees and thus improving performance if there are no conflicts and disagreements between the members of the team based on differences in Nationality and intolerance, for example, nationality predominant workers, which may affect the exchange of experiences and information in the channels of communication and thus adversely affect the performance of missions and achieve goals. Hence, the researchers recommend managers and decision makers to focus on creating a harmonious fabric of different nationalities working towards improving the performance and raising the efficiency of the organization

The study showed a positive effect of age diversity on job performance of the employees in hotel sector in Jordan. The retention of older staff members adds rationality and consistency to the decision-making process of the various task forces and reduces conflicts. The conflicts that can occur between workers of the same age group, which makes the teams more coherent and to achieve the objectives. So managers and decision makers in hotels have to hire young employees with high qualifications and capabilities in modern technologies, which can contribute to increasing the skill of senior employees in the technology, and thus improve their performance more. The youth's blood flow in the organizations may give them a higher risk tolerance advantage which will increase Profits and benefits through the exploitation of new opportunities.

The study focused on only four diversity magnitudes - gender, education, age and nationality - which may have restricted the strength of the research. A future study can be conducted with same title with more diversity variables such as; Ethnicity, Family status, life style. Also, the sample size used may have accounted in part for the research result. A study with larger sample can be conducted for better generalization. A comparison of the effect of workforce diversity on similar or the same organizations operating in different countries would improve the depth of knowledge, especially on the interaction of organizational culture and national environment, and the effect of workforce diversity further. For further understanding, a study can focus on a specific category (positions in the organization like Directors, Managers or Executives) of employees.

\section{References}

Akinnusi, D. M., Sonubi, O. O., \& Oyewunmi, A. E. (2017) Fostering Effective Workforce Diversity Management in Nigerian Organizations: The Challenge of Human Resource Management. International Review of Management and Marketing, 7(2), 108-116.

Al-Ahmad, R. S., \& Alkhawlani, M. (2017). The Effect of Workforce Diversity on Employee Performance: Conceptual Framework. IJRDO-Journal of Business Management, 3(3), 53-57.

Al-Hawary, S. I. S. (2015). Human Resource Management Practices as a Success Factor of Knowledge Management Implementation at Health Care Sector in Jordan. International Journal of Business and Social Science, 6(11), 83-98. 
Al-Hawary, S. I. S., \& Alajmi, H. M. (2017). Organizational Commitment of the Employees of the Ports Security Affairs of the State of Kuwait: The Impact of Human Recourses Management Practices. International Journal of Academic Research in Economics and Management Sciences, 6(1), 52-78.

Al-Hawary, S. I. S., \& AL-Hamwan, A. M. (2017). Environmental Analysis and its Impact on the Competitive Capabilities of the Commercial Banks Operating in Jordan. International Journal of Academic Research in Accounting, Finance and Management $\quad$ Sciences, $7(1), \quad$ 277-290. https://doi.org/10.6007/IJARAFMS/v7-i1/2701

Al-Hawary, S. I. S., \& Al-Namlan, A. A. (2018). Impact of Electronic Human Resources Management on the Organizational Learning at the Private Hospitals in the State of Qatar. Global Journal of Management and Business Research: A Administration and Management, 18(7), 1-11.

Al-Hawary, S. I. S., \& Metabis, A. (2012)0 Implementation of Internal Marketing in Jordan Banks. International Journal of Data Analysis and Information, 4(1), 37-53.

Al-Hawary, S. I. S., \& Nusair, W. K. (2017). Impact of Human Resource Strategies on Perceived Organizational Support at Jordanian Public Universities. Global Journal of Management and Business Research: A Administration and Management, 17(1), 68-82.

Al-Hawary, S. I. S., \& Shdefat, F. A. (2016). Impact of Human Resources Management Practices on Employees' Satisfaction A Field Study on the Rajhi Cement Factory. International Journal of Academic Research in Accounting, Finance and Management Sciences, 6(4), 274-286.

Al-Hawary, S. I. S., Al-Kumait, Z. H. (2017). Training programs and their impact on the employees' performance at King Hussain Bin Talal Development Area at Al-Mafraq Governate in Jordan. International Journal of Academic Research in Economics and Management Sciences, (1), 258-274.

Al-Hawary, S. I. S., Al-Qudah, K. A., Abutayeh, P. M., Abutayeh, S. M., \& Al-Zyadat, D. Y. M. (2013). The impact of internal marketing on employee's job satisfaction of commercial banks in Jordan. Interdisciplinary Journal of Contemporary Research in Business, 4(9), 811-826.

Anitha, J. (2014). Determinants of employee engagement and their impact on employee performance. International Journal of Productivity and Performance Management, 63(3), 308-323. https://doi.org/10.1108/IJPPM-01-2013-0008

Ankita, S. (2014). Workforce Diversity: A Key to Improve Productivity. Economics and Finance, 11, 76-85.

Armstrong, C., Flood, P. C., Guthrie, J. P., Liu, W., MacCurtain, S., \& Mkamwa, T. (2010). The impact of diversity and equality management on firm performance: beyond high performance work systems. Human Resource Management, 49(6), 977-998. https://doi.org/10.1002/hrm.20391

Awadh, A. M., \& Wan Ismail, W. (2012). The impact of personality traits and employee work-related attitudes on employee performance with the moderating effect of organizational culture: the case of Saudi Arabia. Asian Journal of Business and Management Sciences, 1(10), 108-127.

Backes-Gellner, U., \& Veen, S. (2009). The impact of aging and age diversity on company performance.

Bass, B. M., Avolio, B. J., Jung, D. I., \& Berson, Y. (2003). Predicting unit performance by assessing transformational and transactional leadership. Journal of Applied Psychology, 88(2), 207-218. https://doi.org/10.1037/0021-9010.88.2.207

Bedi, P., Lakra, P., \& Gupta, E. (2014). Workforce Diversity Management: Biggest Challenge Or Opportunity For 21 st Century Organizations.

Borman, W. C., \& Motowidlo, S. J. (1993). Expanding the criterion domain to include elements of contextual performance. In N. Schmitt, \& W. C. Borman (Eds.), Personnel selection in organizations (pp. 71-98). San Francisco: Jossey-Bass.

Borman, W. C., \& Motowidlo, S. J. (1997). Task performance and contextual performance: The meaning for personnel selection research. Human Performance, 10, 99-109. https://doi.org/10.1207/s15327043hup1002_3

Cadrain, D. (2008). Sexual equity in the workplace . HR Magazine, 53(9), 44-48.

Campbell \& Wise. (1990). Modeling Job Performance in A Population of Jobs. Personal Psychology, (43), 313-333.

Carrell, M. R., Mann, E. E., \& Sigler, T. H. (2006). Defining workforce diversity programs and practices in 
organizations: A longitudinal study. Labor Law Journal, 57(1), 5-12.

Chatman, J. A., \& Flynn, F. J. (2001). The influence of demographic heterogeneity on the emergence and consequences of cooperative norms in work teams. Academy of Management Journal, 44(5), 956-974.

Chew, W., Lee, M., Tan, C., \& Tee, F. (2011). The effects of workforce diversity towards the employee performance in an organization.

Choi, S., \& Rainey, H. G. (2010). Managing diversity in US federal agencies: Effects of diversity and diversity management on employee perceptions of organizational performance. Public Administration Review, 70(1), 109-121. https://doi.org/10.1111/j.1540-6210.2009.02115.x

Darwin, J. R., \& Palanisamy, C. S. (2015). The Effects of Work Force Diversity on Employee Performance in Singapore Organisations. International Journal of Business Administration, 6(2), 17-29.

Dessler, G. (2011). Human resource management (12th ed.). New Delhi: Pearosn Education.

Dike, P. (2013). The Impact of Workplace Diversity on Organisations. (Degree Thesis). Retrieved October 28, 2016, from https://www.theseus.fi/bitstream/handle/10024/63581/Thesisxx

Durga, P. R. (2017). The Impact of Workforce Diversity on Organizational Effectiveness:(A Study of Selected Banks in Tigray Region of Ethiopia). International Journal of Science and Research (IJSR), 6(1), 427-434. https://doi.org/10.21275/29121604

Edwards, J. R. (1991). Person -job fit: A conceptual integration, literature review, and methodological critique. In C. L. Cooper \& I. T. Robertson (Eds.), International review of industrial and organizational psychology (Vol. 6, pp. 283-357). Chichester, UK: John Wiley \& Sons, Ltd.

Ehimare, O. A., \& Ogaga-Oghene, J. O. (2011). The Impact of workforce diversity on Organizational effectiveness: A study of Nigerian banks, Annals of the University of Petroşani. Economics, 11(3), 93-110.

Esty, K. C., Griffin, R., \& Hirsch, M. S. (2015). Workplace diversity. Adams Media.

Evans, C. (2014). Diversity management and organizational change. Equality, Diversity and Inclusion: An International Journal, 33(6), 482-493. https://doi.org/10.1108/EDI-09-2013-0072

Farooqui, M. S., \& Nagendra, A. (2014). The Impact of person organization fit on job satisfaction and performance of the employees. Procedia economics and Finance, 11, 122-129. https://doi.org/10.1016/S2212-5671(14)00182-8

Feely, A. J., \& Harzing, A. W. (2003). Language management in multinational companies. Cross Cultural Management: An International Journal, 10, 37-52. https://doi.org/10.1108/13527600310797586

Gacheri, M. M. (2012). Effect of Workforce Diversity Management on Employee Performance In The Banking Industry In Kenya. DBA Africa Management Review, 3(1), 1-21.

Gehrels, S., \& Suleri, J. (2016). Diversity and inclusion as indicators of sustainable human resources management in the international hospitality industry. Research in Hospitality and Management, 6(1), 61-67. https://doi.org/10.2989/RHM.2016.6.1.8.1296

Greenberg, J. (2012). Diversity in the Workplace: Benefits, Challenges and Solutions. Retrieved on February 27, 2014 from http://diversity.sdce.edu/content/diversity-workplace-benefits-challenges-and-solutions

Gupta, R. (2013). Workforce diversity and organizational performance. International Journal of Business and Management Invention, 2(6), 36-41.

Hafiza, S. I., \& Faiza, M. S. (2015). Impact of workforce diversity on organizational performance in the education sector of Karachi Pakistan. International Journal of Scientific \& Engineering Research, 6(10), 1258-1273.

Hickman, D. C. (2009). The effects of higher education policy on the location decision of individuals: Evidence from Florida's Bright Futures Scholarship Program. Regional science and urban Economics, 39(5), 553-562. https://doi.org/10.1016/j.regsciurbeco.2009.04.002

Holton, E. F. III., \& Yamkovenko, B. (2008). Strategic Intellectual Capital Development: A Defining Paradigm for HRD? Sage Publications. Human Resource Development Review, 7(3), 270-291. https://doi.org/10.1177/1534484308321360

Hunt, S. T. (1996). Generic work behavior: An investigation into the dimensions of hourly job performance. Personnel Psychology, 49, 51-83. https://doi.org/10.1111/j.1744-6570.1996.tb01791.x

Jackson, S. E., \& Joshi, A. (2004). Diversity in social context: a multi-attribute, multilevel analysis of team 
diversity and sales performance. Journal of organizational Behavior, 25(6), 675-702. https://doi.org/10.1002/job.265

Kravitz, D. A. (2003). More women in the workplace: is there a payoff in firm performance? The Academy of Management Executive, 17(3), 148-149.

Kreitz, P. A. (2008). Best practices for managing organizational diversity. The Journal of Academic Librarianship, 34, 101-120. https://doi.org/10.1016/j.acalib.2007.12.001

Kyalo, J. M. K. (2015). Effect of Diversity in Workplace on Employee Performance in The Banking Industry in Kenya. Strategic Journal of Business and Change Management, 2(5), 608-627.

Le, C. N. (2008). How effective is Diversity Training? Everyday Sociology Blog.

Lu, B. J., Guo, X. H., Luo, N. L., \& Chen, G. Q. (2015). Corporate Blogging and Job Performance: Effects of Work-related and Nonwork-related Participation. Journal of Management Information Systems, 32(4), 285-314. https://doi.org/10.1080/07421222.2015.1138573

Mafuzah, M., \& Juraifa, J. (2016). Emotional Intelligence and Job Performance: A Study Among Malaysian Teachers. Science Direct Procedia Economics and Finance, 35, 674-682. https://doi.org/10.1016/S2212-5671(16)00083-6

Mamman, A. (1996). A diverse employee in a changing workplace. Organization Studies, 17(3), 449-477. https://doi.org/10.1177/017084069601700305

McCloy, R. A., Campbell, J. P., \& Cudeck, R. (1994). A confirmatory test of a model of performance determinants. Journal of Applied Psychology, 79, 493-505. https://doi.org/10.1037/0021-9010.79.4.493

Mercy, G. M. (2012). Workforce Diversity Management and Employee Performance in The Banking Sector in Kenya. Africa Management Review, 3(1), 1-21. https://doi.org/10.1504/IJSOM.2013.054445

Metabis, A., \& Al-Hawary, S. I. S. (2013). The impact of Internal Marketing Practices on Services Quality of Commercial Banks in Jordan. International Journal of Services and Operations Management (IJSOM), 13(3), 313-337.

Mihalcea, A. (2013). The Impact of Leader's Personality on Employees' Job Satisfaction. Procedia-Social and Behavioral Sciences, 78, 90-94. https://doi.org/10.1016/j.sbspro.2013.04.257

Mohammed et al. (2013). Mohammed, A., S., Nassar, M., E., Ghallab, S., A., \& Morsy, S. M. (2013). Nurses Managers' Decision Making styles and It's Effect on Staff Nurses' Job Performance. Journal of American Science 9(12), 171-179.

Mor Barak, M. E. (2011). Managing diversity: toward a globally inclusive workplace. California: Sage Publications. Economics and Finance, 11, 76-85.

Moretti, E. (2004). Estimating the social return to higher education: evidence from longitudinal and repeated $\begin{array}{lllll}\text { cross-sectional data. Journal of econometrics, } & 121(1), & 175-212 .\end{array}$ https://doi.org/10.1016/j.jeconom.2003.10.015

Motowidlo, S. J. (2003). Job performance. In W. C. Borman, D. R. Ilgen \& R. J. Klimoski (Eds.), Handbook of psychology (Vol. 12, pp. 39-53). Hoboken, NJ: Wiley. https://doi.org/10.1002/0471264385.wei1203

Nadiah, M. A., Ghani, N. S. N. M., Yunus, N., \& Saiful, B. (2016). Leader's Personality Traits and Employees Job Performance in Public Sector, Putrajaya. Procedia Economics and Finance, 37, 46-51. https://doi.org/10.1016/S2212-5671(16)30091-0

Nooraei, M., \& Arasi, I. S. (2011). Emotional intelligence and faculties' academic performance: The social competencies approach. International Journal of Education Administration and Policy Studies, 2(4), 45-52.

Ogbo, A. I., Anthony, K. A., \& Ukpere, W. I. (2014). The Effect of Workforce Diversity on Organizational Performance of Selected Firms in Nigeria. Mediterranean Journal of Social Sciences, 5(10), 231-236. https://doi.org/10.5901/mjss.2014.v5n10p231

Platisa, Ch., Reklitis, P., \& Zimeras, S. (2015). Relation between job satisfaction and job performance in healthcare services. Procedia - Social and Behavioral Sciences, 175, 480-487. https://doi.org/10.1016/j.sbspro.2015.01.1226

Reilly, R. R. A., \& Zvi, H. (2012). In James W. Smither and Manuel London (Eds.), Performance Management: Putting Research into Practice. Available from: ZviAronson. 
Rizwan, M. K. M., Nazar, N. B., \& Qalb, E. A. (2016). The Impact of Workforce Diversity Towards Employee Performance: Evidence from Banking Sector of Pakistan. American Journal of Marketing Research, 2(2), 53-60.

Robbins, S. P., \& Judge, T. A. (2009). Essentials of organizational behavior (10th ed.). Pearson Prentice Hall.

Rogelberg, S. G., \& Rumery, S. M. (1996). Gender diversity, team decision quality, time on task, and interpersonal cohesion. Small Group Research, 27(1), 79-90. https://doi.org/10.1177/1046496496271004

Salanova, M., Lorente, L., Chambel, M. J., \& Martinez, I. M. (2011). Linking transformational leadership to nurses' extra-role performance: The mediating role of self-efficacy and work engagement. Journal of Advanced Nursing, 67, 2256-2266. https://doi.org/10.1111/j.1365-2648.2011.05652.x

Salgado, J. F. (2017). Moderator effect of job complexity on the validity of forced-choice personality inventories for predicting job performance. Journal of Work and Organizational Psychology, 33, 229-238. https://doi.org/10.1016/j.rpto.2017.07.001

Saltson, E., \& Özgür, E. (2015). Impact Of Workforce Diversity On A Business Organization's Non-Financial Performance, With Moderation By Leadership Style And Perceived Organizational Support. International Journal of Economics, Commerce and Management, 3(5), 160-179.

Scullen, S. E., Mount, M. K., \& Goff, M. (2000). Understanding the latent structure of job performance ratings. Journal of Applied Psychology, 85(6), 956-970. https://doi.org/10.1037/0021-9010.85.6.956

Singh, K. (2016). Influence of Internal Service Quality on Job Performance: A Case Study of Royal Police Department. Procedia - Social and Behavioral Sciences, 224, 28-34. https://doi.org/10.1016/j.sbspro.2016.05.396

Stazyk, E. C., Davis, R. S. Jr., \& Liang, J. Q. (2012). Examining the links between workforce diversity, organizational goal clarity, and job satisfaction. The 2012 Annual Meeting and Exhibition of the American Political Science Association. New Orleans, LA (August 30 - September 2, 2012).

Thomas, D. A. (2004). Diversity as strategy. Harvard Business Review, 82(9), 98-98.

Uchhal, D. S., \& Solkhe, A. (2017). An empirical investigation of relationship between emotional intelligence and job performance in Indian manufacturing sector clear. International Journal of Research in Commerce \& Management, 8(7), 18-21.

Uschi, B. G., \& Stephan, V. (2013). Positive effects of ageing and age diversity in innovative companies Large-scale empirical evidence on company productivity. Human Resource Management Journal, 23(3), 279-295. https://doi.org/10.1111/1748-8583.12011

Viswesvaren, C., \& Ones, D. S. (2000). Perspectives on models of job performance. International Journal of Selection and Assessment, 8, 216-226. https://doi.org/10.1111/1468-2389.00151

Vithanage, V., \& Arachchige, B. J. H. (2017). A Study on the Work-Family Balance and Job Performance of Academics in Sri Lanka. IUP Journal of Management Research, 16(2), 7-28.

Wambui, T. W., Wangombe, J. G., Muthura, M. W., Kamau, A. W., \& Jackson, S. M. (2013). Managing Workplace Diversity: A Kenyan Perspective. International Journal of Business and Social Science, 4(16).

Watkin, C. (2002). Developing Emotional Intelligence. International Journal of Selection and Assessment, 2, 89-92.

Wentling, M., \& Palma-Rivas, N. (1998). Current status and future trends of diversity initiatives in the workplace: Diversity experts' perspective. Human Resource Development Quarterly, 9(3), 235-253. https://doi.org/10.1002/hrdq.3920090304

Williams, K. Y., \& O’Reilly, C. A. III. (1998). A Review Of 40 Years Of Research. Research in Organizational Behavior, 20, 77-140.

\section{Copyrights}

Copyright for this article is retained by the author(s), with first publication rights granted to the journal.

This is an open-access article distributed under the terms and conditions of the Creative Commons Attribution license (http://creativecommons.org/licenses/by/4.0/). 